\title{
Translators' Preface
}

Every act of translation requires negotiation and compromise, especially with two translators collaborating on the same text. We agreed from the outset that we wanted to re-create as closely as possible the experience of reading the German original. Both of us are fluent in English and German, but both of us are also native speakers of just one language. We naturally disagreed about nuances of tone and style in the original and the translation, though we were in agreement about the content and the direction of the argument. Kurt Flasch's style is unique, subtle, and careful: how he says something is nearly as important as what he says. It is in terms of the "how" that we had to make compromises. A subtlety in the German that one of us found important could not always be re-created without introducing alienating diction into the English version, and we therefore decided to retain Flasch's idiosyncrasies only where the German is equally peculiar.

A few of these idiosyncrasies merit special mention. Flasch's style oscillates between the formal and the conversational and is aimed at a learned and curious general audience, not just specialists. At times his tone may border on the irreverent, and Flasch delights in wordplay and vivid images, some of them taken from German daily life. In our translation we have attempted to keep the text equally whimsical.

Flasch's style also relies on a flexible terminology: the same philosophical concepts are often presented with German synonyms. We have collapsed some of these synonyms to make the text more readable in English, but without sacrificing variation completely. In this context our use term "being" deserves a special note. It represents the German terms Wesen, Sein, and Seiendes to avoid unnecessary complications. We have followed Flasch more closely in his use of compounds by breaking them apart and translating each part literally wherever possible. Flasch often eschews Latinisms in favor of 
words with Germanic roots to avoid the impression of loftiness and mysticism attached to many modern interpretations of Eckhart. Latinate words have a more elevated sense in German than they do in English, but we have also tended to avoid Latinisms where possible - with the caveat that they were sometimes inevitable. Readers familiar with Eckhart scholarship will therefore encounter certain terms that seem new or different from those to which they are accustomed.

Finally, two typographical decisions deserve mention. First, Kurt Flasch repeatedly uses colons to connect main clauses. We have kept this important facet of his style to preserve the author's unique voice. Second, we have chosen to capitalize certain nouns, such as Oneness, Wisdom, and Justice, when they refer to the primary determinations. The precise relationship between these primary determinations and their existence in specific entities is developed throughout Flasch's reading of Eckhart, but those who wish to acquaint themselves with the distinction between "Wisdom" and "wisdom," for example, can refer to Flasch's discussion of the prologues to the Opus Tripartitum on pages 77 to 82 for a preliminary explanation.

We are indebted to our copyeditor Kip Keller and the anonymous reader for their attentive reading of the manuscript. They offered many suggestions for improvement, prevented us from introducing inconsistencies, and caught various typos. Their invaluable comments helped us wade through and rethink many thorny issues, and both their eye for detail and their deep understanding of the content helped us improve the text at several stages. 